\title{
A multicomponent prehabilitation pathway to reduce the incidence of delirium in elderly patients in need of major abdominal surgery: study protocol for a before-and-after study
}

Ties L. Janssen ${ }^{1 *}$ (D), Christina A. Mosk', Chantal C. H. A. van Hoof-de Lepper ${ }^{1}$, Daphne Wielders', Tom C. J. Seerden², Ewout W. Steyerberg ${ }^{3}$, Adriaan J. van Gammeren ${ }^{4}$, Dominique C. de Lange ${ }^{5}$, René van Alphen ${ }^{6}$, Martine van der Zee7, René M. de Bruijn", Jolanda de Vries ${ }^{9,10}$, Jan H. Wijsman', Gwan H. Ho ${ }^{1}$, Paul D. Gobardhan ${ }^{1}$ and Lijckle van der Laan ${ }^{1}$

\begin{abstract}
Background: Due to the increase in elderly patients who undergo major abdominal surgery there is a subsequent increase in postoperative complications, prolonged hospital stays, health-care costs and mortality rates. Delirium is a frequent and severe complication in the 'frail' elderly patient. Different preoperative approaches have been suggested to decrease incidence of delirium by improving patients' baseline health. Studies implementing these approaches are often heterogeneous, have a small sample and do not provide high-quality or successful strategies. The aim of this study is to prevent postoperative delirium and other complications by implementing a unique multicomponent and multidisciplinary prehabilitation program.

Methods: This is a single-center controlled before-and-after study. Patients aged $\geq 70$ years in need of surgery for colorectal cancer or an abdominal aortic aneurysm are considered eligible. Baseline characteristics (such as factors of frailty, physical condition and nutritional state) are collected prospectively. During 5 weeks prior to surgery, patients will follow a prehabilitation program to optimize overall health, which includes home-based exercises, dietary advice and intravenous iron infusion in case of anaemia. In case of frailty, a geriatrician will perform a comprehensive geriatric assessment and provide additional preoperative interventions when deemed necessary. The primary outcome is incidence of delirium. Secondary outcomes are length of hospital stay, complication rate, institutionalization, 30-day, 6and 12-month mortality, mental health and quality of life. Results will be compared to a retrospective control group, meeting the same inclusion and exclusion criteria, operated on between January 2013 and October 2015. Inclusion of the prehabilitation cohort started in November 2015; data collection is ongoing.

(Continued on next page)
\end{abstract}

\footnotetext{
* Correspondence: tjanssen@amphia.nl

'Department of Surgery, Amphia Hospital, P.O. Box 90518, 4800 RK Breda,

The Netherlands

Full list of author information is available at the end of the article
}

(c) The Author(s). 2019 Open Access This article is distributed under the terms of the Creative Commons Attribution 4.0 International License (http://creativecommons.org/licenses/by/4.0/), which permits unrestricted use, distribution, and reproduction in any medium, provided you give appropriate credit to the original author(s) and the source, provide a link to the Creative Commons license, and indicate if changes were made. The Creative Commons Public Domain Dedication waiver (http://creativecommons.org/publicdomain/zero/1.0/) applies to the data made available in this article, unless otherwise stated. 
(Continued from previous page)

Discussion: This is the first study to investigate the effect of prehabilitation on postoperative delirium. The aim is to provide evidence, based on a large sample size, for a standardized multicomponent strategy to improve patients' preoperative physical and nutritional status in order to prevent postoperative delirium and other complications. A multimodal intervention was implemented, combining physical, nutritional, mental and hematinic optimization. This research involves a large cohort, including patients most at risk for postoperative adverse outcomes.

Trial registration: The protocol is retrospectively registered at the Netherlands National Trial Register (NTR) number: NTR5932. Date of registration: 05-04-2016.

Keywords: Prehabilitation, Multicomponent, Prevention, Delirium, Geriatric patient, Colorectal surgery, Abdominal aortic aneurysm, Quality of life

\section{Background}

The world's population is aging, which subsequently leads to an increase in age-related diseases and conditions. Two major age-related diseases are colorectal carcinoma (CRC) and abdominal aortic aneurysm (AAA), which account for a large percentage of complications and prolonged length of hospital stay [1]. CRC is the third most frequent oncologic disease in the world in both men and women [2-4], with over $50 \%$ of patients being older than 70 . People between 70 and 74 years old are most frequently diagnosed with CRC [3]. The cornerstone for treating CRC remains laparoscopic or open surgery [5]. Prevalence of AAA increases with age and ranges from $1.3 \%$ in women to between 4 and $7.7 \%$ in men over 65 years, with men having a six-fold greater risk [6]. AAA can be surgically treated via either open or endovascular aortic repair.

Up to $30 \%$ of patients undergoing major abdominal surgery and up to $35 \%$ of patients in CRC surgery develop postoperative complications [7, 8]. Old age increases the risk of complications and unplanned readmissions, which in turn lead to a longer hospital stays, higher mortality rates and a decrease in quality of life $[8,9]$.

Physical resilience decreases with age, while frailty increases [10]. Frailty is defined as a state of increased vulnerability which makes the ability to cope with the physical stress associated with surgery and other acute stressors compromised [11]. Incidence rates of frailty have been described of up to $43 \%$ in the population of CRC patients [12]. These frail patients have a four-fold greater risk of major postoperative complications [13], with longer hospital stay and higher 30-day readmission rates after both colorectal surgery and abdominal aortic repair $[14,15]$. Delirium is a frequent postoperative complication in the frail elderly population, with incidence rates described of $25 \%$ after major elective surgery and up to $50 \%$ after high-risk procedures $[16,17]$.

Despite advances such as minimally invasive surgery, protocols to prevent surgical site infection and fast-track protocols, which have decreased the impact of surgically induced trauma and the number and severity of postoperative complications, incidence rates of delirium remain high [18-22]. Additionally, many short- and long-term complications are still observed and occur in elderly patients especially, with even worse outcomes in the frail [23-25]. Several preoperative programs have been suggested to tackle factors of frailty and further reduce postoperative complications such as delirium in the elderly population. Some programs are specifically developed to prevent delirium, since delirium is independently associated with serious adverse outcomes such as functional decline, cognitive decline, increased length of hospital stay and ICU stay, institutionalization, increase of health-care costs and increased mortality rates [24, 26].

Primary prevention is the most effective strategy for minimizing occurrence of delirium as well as delirium-associated complications [27], with favorable outcomes in multicomponent (non-pharmacological) interventions as concluded by two systematic reviews and meta-analyses $[28,29]$. Although of questionable quality, different pharmacological and non-pharmacological preoperative preventive approaches have been trying to further reduce the incidence of postoperative delirium during admission. Pharmacologic interventions proved unsuccessful and the quality of current evidence for improvement with non-pharmacological approaches was labeled moderate [28].

Over the past few years, different studies have suggested 'prehabilitation' programs to reduce postoperative complications. Prehabilitation is a preparatory intervention, prior to admission, aiming at optimizing patients' physiologic reserves in anticipation of a forthcoming physiological stressor and minimizing peri- and postoperative adverse events [7]. Uni-, bi- and trimodal approaches have been investigated to tackle factors of frailty and to reduce postoperative complications in both CRC and AAA patients [7, 28-40]. The main focus was to improve muscle strength, cardiopulmonary condition, undernourishment or psychological problems, often with 
functional capacity as primary outcome. All studies performed were heterogeneous in composition and factors they tried to influence [37], which makes it impossible to pool results and provide high-quality evidence. Therefore, two recent systematic reviews concluded that there currently is no clear evidence showing that improved preoperative fitness will translate into a decrease in postoperative complications [7, 39].

Previous prehabilitation trials often involved a small number of patients undergoing the prehabilitation program, not exceeding 75 patients. These trials did not focus on elderly patients specifically, with a mean age often below 70. Few studies used health related quality of life as primary or secondary outcome and none of these studies focused specifically on preventing postoperative delirium [37].

Up to $75 \%$ of patients with CRC suffer from iron deficiency anaemia and even mild anaemia can have impaired functional capacity or postoperative delirium as a consequence [24, 40,41]; yet hematinic optimization is often not included in a multicomponent prehabilitation pathway [42]. Patients receiving perioperative red blood cell transfusions because of this anaemia have an increased risk of adverse clinical outcomes, including increased delirium and mortality rates $[43,44]$. It is therefore important to optimize hemoglobin levels before surgery and prevent the need for this transfusion.

The aim of this study is to reduce the incidence of delirium by implementing a unique combined pharmacological and non-pharmacological multidisciplinary program in order to optimize overall fitness in the elderly patients before CRC resection or AAA repair. By implementing this preoperative program, combined with the above-mentioned SSI and ERAS protocols, the primary goal is to reduce the incidence of postoperative delirium. Secondary goals are to reduce other postoperative complications, shorten hospital stay, prevent unplanned ICU admission, reduce mortality rates and improve prehabilitated patients' quality of life postoperatively. If reduction of delirium incidence proves successful, a health-economic analysis will be performed to assess cost-effectiveness. If subsequent results prove (cost-) effective, nationwide implementation is the objective.

\section{Methods}

\section{Design and setting of the study}

This protocol describes a single-center controlled before and after study with an intention-to-treat design. A unique multidisciplinary care pathway is designed, starting at the 70PLUS outpatient clinic of the department of surgery of the Amphia hospital Breda, a tertiary teaching hospital in the Netherlands. Table 1 provides an overview of the complete study period, from inclusion to 12 months follow-up.

\section{Patient characteristics and recruitment}

All patients aged 70 and older who are scheduled to undergo elective abdominal surgery in case of CRC or AAA, at the Amphia hospital are assessed for eligibility. They will undergo robot-assisted laparoscopic resection, laparoscopic resection or open removal of the colorectal tumor, or EVAR or open aortic repair of their AAA.

Patients are considered ineligible if acute hospitalization or acute surgery is needed (necessity established by the gastroenterologist, gastrointestinal surgeon or vascular surgeon), if they had surgery 6 months prior or if surgery is planned within 2 weeks of the multidisciplinary meeting.

Eligibility for participation is established at the multidisciplinary meetings for colorectal cancer and for vascular surgery. After this establishment, patients are invited to participate by the gastroenterologist or the vascular surgeon. If preoperative chemotherapy, radiotherapy or chemoradiation is indicated, patients are included in the study when the indication for surgery is made, prior to these neoadjuvant therapies. Patients receive oral and written information about the study. If patients agree to participate, they are invited by the primary investigator to visit the 70PLUS outpatient clinic. Written informed consent will be obtained from all study participants during this visit. Due to the design of the study and the electronic patient file, it is not possible to blind participants, investigators, care providers, or outcome assessors in this study.

\section{The 70PLUS outpatient clinic}

All patients will visit a trained nurse practitioner and a physical therapist at the 70PLUS outpatient clinic. A dietician and a geriatrician will be consulted in case of undernourishment or frailty respectively. Each visit to the healthcare providers takes approximately 1 hour. The visit to a geriatrician is planned on a separate day because of the major burden of a four-hour visit.

In the optimal situation, patients have 5 weeks prior to surgery to optimize their overall fitness, starting from the moment they visit the 70PLUS outpatient clinic. Patients in need of neoadjuvant treatment will have a longer optimization period, however this advantage will likely be nullified by the burden of these treatments. Patients are invited to visit the outpatient clinic when indication for surgery is made. Time of surgery is based on the surgical program and physical complaints of the patient at that moment.

The nurse practitioner screens for frailty and determines the need for consulting the other physicians. Indications for consulting these physicians are described in Table 1. The following baseline patient characteristics are assessed: age, gender, surgical and general medical history, comorbidities, use of medication, intoxications, 
Table 1 Complete overview of the study period

\begin{tabular}{|c|c|c|c|c|c|c|c|c|c|}
\hline \multirow[t]{3}{*}{ Time point } & \multicolumn{9}{|l|}{ Study period } \\
\hline & \multicolumn{2}{|c|}{ Eligibility assessment } & \multirow{2}{*}{$\begin{array}{l}\text { Trial } \\
\text { enrollment } \\
\text { T0 - Informed } \\
\text { consent obtained }\end{array}$} & \multirow{2}{*}{$\begin{array}{l}\text { 7OPLUS } \\
\text { outpatient } \\
\text { clinic } \\
\mathrm{T} 1\end{array}$} & \multirow{2}{*}{$\begin{array}{l}\text { Admission } \\
\text { T2 }\end{array}$} & \multirow{2}{*}{$\begin{array}{l}\text { Discharge } \\
\text { T3 }\end{array}$} & \multirow{2}{*}{$\begin{array}{l}\text { Discharge } \\
+2 \text { weeks } \\
\text { T3.5 }\end{array}$} & \multirow{2}{*}{$\begin{array}{l}\text { 6-months } \\
\text { follow-up } \\
\text { T4 }\end{array}$} & \multirow{2}{*}{$\begin{array}{l}\text { 12-months } \\
\text { follow-up } \\
\text { T5 }\end{array}$} \\
\hline & $\begin{array}{l}\text { Pathology } \\
\text { result/ CTA }\end{array}$ & $\begin{array}{l}\text { Multidisciplinary } \\
\text { meeting }\end{array}$ & & & & & & & \\
\hline \multicolumn{10}{|l|}{ Assessments } \\
\hline Laboratory testing & & & & $x$ & $x$ & $x$ & & & \\
\hline \multicolumn{10}{|l|}{ Nurse practitioner or investigator } \\
\hline Baseline patient characteristics & & & & $x$ & & & & & \\
\hline Factors of frailty & & & & $x$ & & & & & \\
\hline MMSE & & & & $x$ & & $x$ & & $x$ & $x$ \\
\hline $\mathrm{CCl}$ and $\mathrm{ASA}$ & & & & $x$ & & & & & \\
\hline P-POSSUM & & & & $x$ & & & & & \\
\hline ISAR-HP & & & & $x$ & & & & $x$ & $x$ \\
\hline PARKER & & & & $x$ & & & & $x$ & $x$ \\
\hline SNAQ & & & & $x$ & & & & & \\
\hline KATZ-ADL & & & & $x$ & & & & $x$ & $x$ \\
\hline Caregiver burden & & & & $x$ & & & $x$ & $x$ & $x$ \\
\hline CESD-16 & & & & $x$ & & & $x$ & $x$ & $x$ \\
\hline WHOQOL-BREF & & & & $x$ & & & $x$ & $x$ & $x$ \\
\hline \multicolumn{10}{|l|}{ Physiotherapist } \\
\hline $10 \mathrm{MWT}$ & & & & $x$ & & & & & \\
\hline TCST & & & & $x$ & & & & & \\
\hline TUG & & & & $x$ & & & & $x$ & $x$ \\
\hline MIP & & & & $x$ & & & & & \\
\hline Handforce & & & & $x$ & & & & & \\
\hline \multicolumn{10}{|l|}{ Dietician } \\
\hline MNA-SF & \multirow{3}{*}{\multicolumn{2}{|c|}{$\begin{array}{l}\text { Indications for referral to dietician: } \\
\text { Unintentional weight loss } \\
\text { Loss of appetite } \\
\text { BMl }<22 \\
\text { Undernourishment }\end{array}$}} & & $x$ & & & & & \\
\hline BMI & & & & $x$ & & & & $x$ & $x$ \\
\hline SNAQ & & & & $x$ & & & & & \\
\hline \multicolumn{10}{|l|}{ Geriatrician } \\
\hline Comprehensive geriatric assessment & $\begin{array}{l}\text { Indications f } \\
\text { Delirium in } ⺊ \\
\text { MMSE } \leq 24 \\
\text { TUG } \geq 12.6 \mathrm{~s} \\
\text { Polypharmac }\end{array}$ & $\begin{array}{l}\text { for referral to geriatrician: } \\
\text { history } \\
\text { cy }\end{array}$ & & $x$ & & & & & \\
\hline \multicolumn{10}{|l|}{ Interventions } \\
\hline \multicolumn{10}{|c|}{ Laboratory testing / Intravenous iron suppletion } \\
\hline All patients & $\begin{array}{l}\text { Single dose } \\
\text { Ferric carbox } \\
\text { at day care } v \\
\text { Hb level mal } \\
\text { Hb level fem }\end{array}$ & $\begin{array}{l}\text { of } 1000 \mathrm{mg} \\
\left.\text { xymaltose (Ferinject }{ }^{\oplus}\right) \\
\text { when indicated: } \\
\text { les }<8,1 \mathrm{mmol} / \mathrm{L} \\
\text { nales }<7,4 \mathrm{mmol} / \mathrm{L}\end{array}$ & & $x$ & & & & & \\
\hline \multicolumn{10}{|l|}{ Physiotherapist } \\
\hline All patients & $\begin{array}{l}30 \text { min of da } \\
\text { cycling } 5 \text { exe } \\
\text { muscle stren } \\
\text { respiratory m } \\
\text { Transfer train } \\
\text { (getting out }\end{array}$ & $\begin{array}{l}\text { aily walking or } \\
\text { ercises to improve leg } \\
\text { ngth } 2 \times 15 \text { minutes } \\
\text { nuscle exercise } \\
\text { ning when indicated } \\
\text { of bed) }\end{array}$ & & $x$ & & & & & \\
\hline
\end{tabular}


Table 1 Complete overview of the study period (Continued)

\begin{tabular}{|c|c|c|c|c|c|c|c|c|c|}
\hline \multirow[t]{3}{*}{ Time point } & \multicolumn{9}{|l|}{ Study period } \\
\hline & \multicolumn{2}{|c|}{ Eligibility assessment } & \multirow{2}{*}{$\begin{array}{l}\text { Trial } \\
\text { enrollment } \\
\text { T0 - Informed } \\
\text { consent obtained }\end{array}$} & \multirow{2}{*}{$\begin{array}{l}\text { 70PLUS } \\
\text { outpatient } \\
\text { clinic } \\
\text { T1 }\end{array}$} & \multirow{2}{*}{$\begin{array}{l}\text { Admission } \\
\text { T2 }\end{array}$} & \multirow{2}{*}{$\begin{array}{l}\text { Discharge } \\
\text { T3 }\end{array}$} & \multirow{2}{*}{$\begin{array}{l}\text { Discharge } \\
+2 \text { weeks } \\
\text { T3.5 }\end{array}$} & \multirow{2}{*}{$\begin{array}{l}\text { 6-months } \\
\text { follow-up } \\
\text { T4 }\end{array}$} & \multirow{2}{*}{$\begin{array}{l}\text { 12-months } \\
\text { follow-up } \\
\text { T5 }\end{array}$} \\
\hline & $\begin{array}{l}\text { Pathology } \\
\text { result/ CTA }\end{array}$ & $\begin{array}{l}\text { Multidisciplinary } \\
\text { meeting }\end{array}$ & & & & & & & \\
\hline \multicolumn{10}{|l|}{ Dietician } \\
\hline Malnourished patients / MNA-SF $<12$ & \multicolumn{3}{|c|}{$\begin{array}{l}\text { Dietary advice on required protein } \\
\text { and calorie intake. } \\
\text { Proteins: } 1.2 \mathrm{~g} / \mathrm{kg} \text { bodyweight } \\
\text { (BMl<30) } \\
\text { Calories: WHO formula for basal } \\
\text { need }+30 \% \text {. Supplements are } \\
\text { provided when required protein } \\
\text { and calorie intake is not met } \\
\text { after dietary advice. }\end{array}$} & \multicolumn{6}{|l|}{$x$} \\
\hline \multicolumn{10}{|l|}{ Geriatrician } \\
\hline Frail patients & \multicolumn{3}{|c|}{$\begin{array}{l}\text { Non-pharmacological interventions } \\
\text { to reduce risk of delirium. } \\
\text { Pharmacological interventions } \\
\text { (prophylaxis). }\end{array}$} & \multicolumn{6}{|l|}{$x$} \\
\hline \multicolumn{10}{|c|}{$\begin{array}{l}\text { Time from pathology result to multidisciplinary meeting: }<1 \text { week. Time from multidisciplinary meeting to T0: }<1 \text { week. Time from T0 to T1: }<1 \text { week. Time from T1 to } \\
\text { admission: } 10 \text { days to } 5 \text { weeks }\end{array}$} \\
\hline \multicolumn{10}{|c|}{$\begin{array}{l}\text { MMSE Mini-Mental State Examination, CCI Charlson Comorbidity Index, ASA American Society of Anaesthesiology, P-POSSUM Portsmouth Physiological and } \\
\text { Operative Severity Score for the Enumeration of Mortality and Morbidity, ISAR-HP Identification of Seniors At Risk - Hospitalized Patients, CES-D16 Centre for } \\
\text { Epidemiological Studies - Depression } 16 \text { questions, WHOQOL-BREF World Health Organisation Quality of Life - BREF, 10MWT 10-m Walk Test, TCST Timed Chair } \\
\text { Stand Test, TUG Timed-up and Go Test, MIP Maximum Inspiratory Pressure, MNA-SF Mini Nutritional Assessment - Short Form, BMI Body Mass Index, SNAQ Short } \\
\text { Nutritional Assessment Questionnaire }\end{array}$} \\
\hline
\end{tabular}

social economic status and schooling, body mass index, home situation (need for home care, institutionalization and social environment), functional dependency (Parker score and Identification of Seniors At Risk - Hospitalized Patients (ISAR-HP) score), psychological history and burden of comorbidity (the American Society of Anesthesiologist (ASA) score, Portsmouth Physiological and Operative Severity Score for the enUmeration of Mortality and Morbidity (P-POSSUM score) and the Charlson comorbidity index (CCI)) [45-48].

Frailty is screened for by collecting information on visual or hearing impairment, sleep rhythm, feeding impairment, dehydration and fall risk. Additional information on frailty is acquired by performing the following questionnaires: the delirium screening checklist, the Groningen frailty score, the KATZ-Activities of Daily Living score (for assessment of functional dependency and mobility) and the Short Nutritional Assessment Questionnaire (SNAQ) (for assessment of nutritional status) [49-51].

A district nurse assesses the need for additional homecare postoperatively for each patient. This assessment will be applied for by the nurse practitioner for all patients who commit to this pathway, in order to shorten the length of hospital stay.

Physiotherapist visit and assessment of physical condition At initial assessment, the physiotherapists measure the patients' cardiopulmonary condition, overall strength and frailty.
Gait, stability and speed are assessed by the Timed Up and Go (TUG) test and the 10-m walking test. These tests are validated and widely used in elderly patients. A cutoff of $12.6 \mathrm{~s}$ is used to define frailty. If considered frail, a geriatrician is consulted. TUG has been found to be superior to ASA-score in identifying oncogeriatric patients who might benefit from a prehabilitation program [52-54]. The timed-chair-stand test is used to assess lower extremity strength, specifically vertical movement and hip muscle strength [55].

Strength of diaphragm and inspiratory muscles is assessed by measuring the maximum inspiratory pressure (MIP) during $1.5 \mathrm{~s}$, using MicroRPM ${ }^{\mathrm{Tm}}$. Training of inspiratory muscles successfully reduces length of hospital stay and postoperative pulmonary complications [56].

Strength of both hands is tested using Hydraulic Hand dynamometer, JAMAR ${ }^{\mathrm{m}}$. Poor handgrip strength is associated with a decline in activities of daily living and cognition in the elderly [57].

In order to lower the burden for patients, lower the health-care costs and increase compliance, the prehabilitation program has a large home-based component. All patients receive personalized exercises to preserve or improve their overall fitness and strength at home, unsupervised. These exercises have to be performed daily. The aim of these exercises is to increase respiratory muscle strength using the Threshold inspiratory muscle trainer ${ }^{\circ}$, and to improve overall fitness by endurance training, which consists of daily walking or cycling for 30 consecutive minutes. Patients receive specific transfer exercises and 
specific exercises to increase muscle strength in both legs and arms. All exercises are individualized to each patient's capabilities, as not every patient has the same baseline motivation or fitness.

Patients are asked to keep a diary with a record of their daily activities to assess compliance with the prehabilitation program. A cut-off value of $75 \%$ or more was considered compliant with the training program.

\section{Dietician consultation and nutritional assessment}

Nutrition is quantified using the body mass index (BMI), the Mini Nutritional Assessment score short form (MNA-SF) and the SNAQ-score [51, 58]. Laboratory research assesses blood levels of folic acid, vitamins B and D, lipid-spectrum and pre-albumin. Indications for consulting the dietician are described in Table 1. Based on the hospital's protocol for patients who will undergo major abdominal surgery, the dietician provides supplemental protein drinks and dietary advice if needed.

\section{Cognition and mental health assessment}

The patient is labeled frail, or at increased risk of developing delirium, if any form of cognitive impairment has previously been diagnosed. Cognition is examined using the Mini-Mental State Examination (MMSE), a standardized questionnaire designed specifically for this purpose [59]. The MMSE has a sensitivity of up to $97 \%$ and specificity of up to $70 \%$, when adjusted for educational level [60]. A score below 24 or 26 points, depending on education level, is also considered an indication of frailty. In these increased-risk cases (see Table 1), the geriatrician will perform a comprehensive geriatric assessment (CGA) [61, 62].

The CGA is an effective method to identify patients with increased risk for postoperative complications [6164]. In the CGA, a geriatrician will assess if additional preventive intervention is necessary (e.g. prescribing prophylactic haloperidol, critically reviewing mediation, and providing advice on non-pharmacologic prevention of infection, falls, pain, anxiety and dehydration). Prophylactic haloperidol to be given during admission is prescribed to cognitively impaired patients and patients with delirium in medical history. The CGA is effective in improving mortality rates after 36 months of follow-up, improving functional independence and physical function and in decreasing rates of institutionalization [65].

Depression is screened for by using the CESD-16 questionnaire, which is a shortened version of the CESD-20 [66, 67]. Caregiver burden will be assessed by using the caregiver strain index questionnaire [68].

Quality of life is assessed using the WHOQOL-BREF. This is a shorter version of the WHOQOL-100, a questionnaire introduced by the World Health Organization. This questionnaire does not assess the physical capabilities of a patient, but assesses the patient's opinion of having or not having these capabilities. This way, it provides a better display of a patient's quality of life compared to questionnaires such as the SL-36, which shows a patient's functional capacity $[69,70]$.

\section{Biochemistry}

Blood is collected from patients at or just before their first visit to the outpatient clinic. The following concentrations are determined via laboratory research: hemoglobin, hematocrit, leukocytes, thrombocytes, MCV, erythrocytes, INR, CRP, sodium, potassium, chloride, urea, creatinine, GFR, pre-albumin, ASAT, ALAT, cholesterol, HDL cholesterol, LDL cholesterol, triglycerides, iron, transferrin, ferritin, folic acid, vitamin B12, 25-OH-Vitamin D and CEA.

Anemic patients (hemoglobin level of $<7.4 \mathrm{mmol} / \mathrm{L}(<$ $120 \mathrm{~g} / \mathrm{L})$ for women and $<8.1 \mathrm{mmol} / \mathrm{L}$ for men $(<130 \mathrm{~g} /$ L)) receive a single dose of $1000 \mathrm{mg}$ Ferric carboxymaltose $\left(\right.$ Ferinject $\left.{ }^{\circ}\right)$ preoperatively to increase hemoglobin levels [71-73]. This is the fastest and safest way of correcting preoperative hemoglobin levels in patients suffering from iron deficiency anaemia [74].

Blood collection and laboratory research will be repeated at admission (preoperative) and at the day of discharge (postoperative).

Table 1 provides a complete overview of cooperating physicians, indications for consulting these physicians, and actions and questionnaires performed by these physicians.

\section{Admission}

For both the control group and the intervention group, standard preventive measures for delirium will be taken during admission according to the HELP guidelines and postoperative patient care will be provided according to ERAS protocols [75].

\section{Follow up}

Patients will be asked to visit the outpatient clinic at six and 12 months after discharge. These visits will last no longer than $20 \mathrm{~min}$. The WHOQoL-BREF, CESD-16, MMSE, TUG, BMI, KATZ-ADL, PARKER and ISAR-HP are scored. Emergency department visits, readmission since initial discharge and deaths during follow-up will be registered. When trial participation is discontinued postoperatively, follow-up data on complications, readmissions, institutionalization and mortality will be acquired through retrospective chart review.

\section{Study outcomes}

The primary study outcome is the incidence of delirium. Delirium will be screened for with the Delirium Observational Screening Score (DOSS), using the shortened 
version which consists of 13 items [76]. The DOSS is scored three times every day. A delirium is likely if the patient has a DOSS of $\geq 3$. If delirium is suspected, a geriatrician will confirm the diagnosis using the DSM-V criteria and the confusion assessment method (CAM) $[77,78]$.

The secondary outcomes are postoperative length of hospital stay, ICU admission, readmissions, institutionalization, mortality within 1 year after surgery, and quality of life. Number and severity of postoperative complications during hospital stay and follow-up will be assessed and scored according to the Clavien-Dindo classification [79, 80].

All other factors of frailty, that are mentioned in sections 2.3 to 2.7 , will be evaluated and analyzed to confirm association with the incidence of delirium.

\section{Statistical analysis}

The sample size was calculated based on data from a previous study [24]. Based on the analysis of 232 patients with AAA or CRC, this study found a delirium incidence of $15 \%$. A $50-50$ trial needs 550 patients, or 275 patients per study arm, to reduce the incidence of delirium to $7.5 \%$. These calculations are based on a power of $80 \%$ with a $5 \%$ two-sided significance level.

Starting in November 2015, the aim is to include 275 patients in the prospective study, which is feasible during approximately 4.0 years of accrual, including follow-up. These patients will be compared to a group of patients treated between January 2013 and October 2015 at the Amphia Hospital Breda, The Netherlands. This group is formed by applying the same inclusion and exclusion criteria as are used to include patients prospectively, they were given the same perioperative care as given to the prehabilitation group, but they did not partake in any prehabilitation program. All baseline characteristics and postoperative outcomes mentioned in previous sections for the control group will be acquired through retrospective chart review, however due to the design of this research it is likely that not all these characteristics have been documented. Data acquired during the six- and 12 months follow-up visits have not been collected for the control group and will only be used for analyses on the prehabilitation group. For example, blood levels cannot be determined through retrospective chart review, however functional dependency can be acquired. The ratio of open versus minimally invasive surgery is expected to be the same in both groups, since conditions and indications for minimally invasive procedures did not change over study time.

Descriptive statistics will be used for presenting baseline characteristics. Differences in these characteristics between the control group and the prehabilitation group will be tested for statistical significance by using Student t-test or Mann-Whitney $U$ test for continuous variables and Pearson chi-squared test or Fisher's Exact test for categorical variables, depending on normality. A subgroup analysis will be performed per diagnosis to test for differences between the groups in the primary and secondary outcomes.

Primary analysis for incidence of delirium will be done by creating a logistic regression model with adjustment for age, history of delirium, ASA $\geq 3$ and diagnosis (AAA or CRC), important prognostic covariates found in previous research [24]. Secondary outcomes will likewise be adjusted for these covariates, however history of delirium will be replaced with type of surgery (open or minimally invasive) [81]. Mixed linear modeling will be applied for measurements over time during follow up. Missing retrospective data will not be multiply imputed.

All data will be gathered in the Amphia Hospital Breda, the Netherlands, using the electronic patient file 'Hyperspace Version IU4 (Epic, Inc., Verona, WI)'.

Statistical analysis will be performed with IBM SPSS statistics software (SPSS Inc., Chicago, Illinois, USA). A two-sided $p$-value $<0.05$ will be considered statistically significant. Data analysis will be done according to the intention-to-treat concept. Data collection is still ongoing.

This article was has been reported by making use of the SPIRIT guidelines [82].

\section{Patient and public involvement}

Patients were not involved in the design of this study, selection of outcome measures, development of research question, and in the recruitment to and conduct of this study. The burden of the intervention will be assessed during follow-up. A brief summary of the results will be made available in Dutch or English to all patients on request.

\section{Discussion}

This new and unique program is a multicomponent and multidisciplinary approach in order to optimize elderly patients in need of major abdominal surgery. The objective of this prehabilitation program is to decrease the incidence of delirium by tackling factors of frailty and by optimizing overall fitness, nutritional status, mental status and anaemia at the same time.

Dutch (SONCOS) guidelines for colorectal cancer suggest an optimal time of 6 weeks from diagnostic pathology results to surgery [83]. The time between the pathology result and the multidisciplinary meeting (MDM) and between the MDM and the 70PLUS outpatient clinic visit is no more than a week, leaving an ideal optimization period of approximately four to 5 weeks. Patients with obstruction or pain will be operated on as soon as possible, thus are not able to finish the entire prehabilitation period. There are no such 
guidelines for AAA surgery, meaning that this patient group should be able to complete the full 5 weeks of prehabilitation.

The combination of AAA and CRC was chosen for this study, even though they are different diseases with their own etiology. Both conditions are a heavy burden on a patient's fitness and are major diseases for which abdominal surgery is required. This combination is justifiable because both diseases have similar surgical risk factors and factors of frailty that increase the risk for a delirium.

Patients are asked to perform unsupervised physical exercises at home, which might reduce compliance because there is no extrinsic motivator. By giving patients tailor-made exercises and by reducing the number of extra hospital visits, better compliance is to be expected [36].

The awareness for delirium in elderly surgical patients has increased in postoperative care, for both doctors and nurses, which might cause a relative increase in delirium cases over time. It is expected that the prehabilitation program will cancel out this effect.

\section{Strengths and limitations}

Compared to other prehabilitation studies, this study aims to include a large prospective and retrospective patient cohort and focusses solely on patients that are $>70$ years. A multimodal approach was implemented, combining both pharmacological and non-pharmacological interventions, involving physical fitness, nutritional status and hemoglobin levels. Previous studies often implemented a single intervention, within a small sample and mean age below 70 [30, 31, 34-37]. With increasing age, physical resilience starts to decrease, which in turn increases the need for prehabilitation, emphasizing the importance of prehabilitation in the elderly.

Due to logistic reasons, not all patients can be visited at admission. Timing of admission makes it impossible to verify improvements in overall fitness, pulmonary muscle strength or the effectiveness of the physical interventions in all patients. In the end, the focus of this research is to prevent delirium and other postoperative adverse events, making quantifying the progress made by the program irrelevant. Previous studies have proven similar programs to be able to make a significant improvement in functional capacity [37].

The design of this study makes the risk of bias fairly high. Due to the before-and-after setting, randomization and blinding of patients and caregivers is impossible. Bias may also occur because surgical procedures have changed over time, although no significant differences are expected due to the consecutive timing of both cohorts.
This study has a single-center design, which may limit generalizability of the study. However, the way this intervention is set-up makes it possible to implement it in other centers as well.

\section{Abbreviations}

AAA: Abdominal aortic aneurysm; ASA: American Society of Anesthesiologist; BMI: Body mass index; CAM: Confusion assessment method; CCl: Charlson comorbidity index; CGA: Comprehensive geriatric assessment; CRC: Colorectal carcinoma; DOSS: Delirium observational screening score; ERAS: Enhanced recovery after surgery; EVAR: Endovascular aortic repair; HELP: Hospital Elder Life Program; ICU: Intensive care unit; ISARHP: Identification of Seniors At Risk - Hospitalized Patients; MDM: Multidisciplinary meeting; MIP: Maximum inspiratory pressure; MMSE: Mini-mental state examination; MNA-SF: Mini nutritional assessment score short form; P-POSSUM: Portsmouth Physiological and Operative Severity Score for the enUmeration of Mortality and Morbidity; SNAQ: Short nutritional assessment questionnaire; SSI: Surgical site infection; TUG: Timed up and go; WHOQOL: World health organization quality of life

\section{Acknowledgements}

The authors would like to acknowledge the professional network of physiotherapists and dieticians at the Amphia hospital, including, J. Creusen, A. de Jong K. van Overveld, A. van de Riet and A. Winnemuller for their support during the setup of this pathway and being involved during the course of this study.

\section{Funding}

This research is funded by an "unrestricted grant" by Amphia Fund for Innovation. Intravenous iron injection, Ferinject ${ }^{\oplus}$ is sponsored by Vifor Pharma. Both funds did not interfere in the study and were not involved in the development of the study design, data collection, management, analysis and interpretation, writing of the report and the decision making to submit this manuscript for publication.

\section{Availability of data and materials}

All data will be kept secure and confidential following institution rules for data storage and will be available to all contributors of this protocol. Dissemination of results will be carried out through publication of scientific articles in peer-reviewed journals and possibly conference presentations.

\section{Authors' contributions}

All authors made a substantial contribution to this bundle of care and scientific writing. TL, CAM, CCH, DW, TCS, AJvG, DCL, RvA, MvdZ, RdB and LvdL made a substantial contribution to the set-up of this protocol and manuscript and are substantially involved in the study. EWS and JdV were involved for statistical analyses. JHW, GHH and PDG were involved in the set up and revising the manuscript and are substantially involved in the study. All authors read and approved the final manuscript.

\section{Ethics approval and consent to participate}

The Medical Ethical Research Committee of Rotterdam, Maasstad Hospita (TWOR) approved the research protocol, ID number NL55694.101.15, in June 2016. Additionally, the Local Research and Development Committee at the Amphia Hospital approved the protocol (Local ID number 1473.16). Serious adverse events and protocol amendments will be reported to this medical ethical committee. Written informed consent will be obtained from all study participants during the first outpatient clinic visit.

\section{Consent for publication}

Not applicable.

\section{Competing interests}

The PhD program of the corresponding author (T.L. Janssen) is funded by an 'unrestricted grant' by Amphia Fund for innovation. All other authors declare that they have no competing interests.

\section{Publisher's Note}

Springer Nature remains neutral with regard to jurisdictional claims in published maps and institutional affiliations. 


\section{Author details}

'Department of Surgery, Amphia Hospital, P.O. Box 90518, 4800 RK Breda, The Netherlands. ${ }^{2}$ Department of Gastroenterology, Amphia Hospital, Breda, The Netherlands. ${ }^{3}$ Department of Public Health, Erasmus MC-University Medical center Rotterdam, Rotterdam, The Netherlands. ${ }^{4}$ Department of Clinical Chemistry and Hematology, Amphia Hospital, Breda, The Netherlands. ${ }^{5}$ Department of Geriatrics, Amphia Hospital, Breda, The Netherlands. ${ }^{6}$ Department of Physical Therapy, Amphia Hospital, Breda, The Netherlands. 'Department of Dieticians, Amphia Hospital, Breda, The Netherlands. ${ }^{8}$ Medical Manager Surgery, Amphia Hospital, Breda, The Netherlands. ${ }^{9}$ Department of Medical Psychology, Elisabeth-TweeSteden Hospital, Tilburg, The Netherlands. ${ }^{10}$ Department of Medical and Clinical Psychology, Tilburg University, Tilburg, The Netherlands.

\section{Received: 20 June 2018 Accepted: 6 March 2019} Published online: 20 March 2019

\section{References}

1. Schilling PL, Dimick JB, Birkmeyer JD. Prioritizing quality improvement in general surgery. J Am Coll Surg. 2008;207(5):698-704

2. Ferlay J, Soerjomataram I, Dikshit R, et al. Cancer incidence and mortality worldwide: sources, methods and major patterns in GLOBOCAN 2012. Int J Cancer. 2015;136(5):E359-86.

3. Cijfers over kanker: IKNL, Nederlandse Kankerregistratie; 2011-2018. Available from: https://www.cijfersoverkanker.nl.

4. Landelijke Richtlijn Gastro Intestinale Tumoren: Oncoline; 2014. Available from: https://www.oncoline.nl/colorectaalcarcinoom.

5. Bruns ER, van den Heuvel B, Buskens CJ, et al. The effects of physical prehabilitation in elderly patients undergoing colorectal surgery: a systematic review. Color Dis. 2016;18(8):0267-77.

6. Robertson L, Nandhra S. Laparoscopic surgery for elective abdominal aortic aneurysm repair. Cochrane Database Syst Rev. 2017;(5):CD012302.

7. Bolshinsky V, Li MH, Ismail H, et al. Multimodal Prehabilitation programs as a bundle of Care in Gastrointestinal Cancer Surgery: a systematic review. Dis Colon Rectum. 2018:61(1):124-38.

8. Brown SR, Mathew R, Keding A, et al. The impact of postoperative complications on long-term quality of life after curative colorectal cancer surgery. Ann Surg. 2014;259(5):916-23.

9. Li LT, Mills WL, White $\mathrm{DL}$, et al. Causes and prevalence of unplanned readmissions after colorectal surgery: a systematic review and meta-analysis. J Am Geriatr Soc. 2013;61(7):1175-81.

10. Schorr A, Carter C, Ladiges W. The potential use of physical resilience to predict healthy aging. Pathobiol Aging Age Relat Dis. 2018;8(1):1403844

11. Chen X, Mao G, Leng SX. Frailty syndrome: an overview. Clin Interv Aging. 2014;9:433-41.

12. Fagard K, Leonard S, Deschodt M, et al. The impact of frailty on postoperative outcomes in individuals aged 65 and over undergoing elective surgery for colorectal cancer: a systematic review. J Geriatr Oncol. 2016;7(6):479-91.

13. Tan KY, Kawamura YJ, Tokomitsu A, et al. Assessment for frailty is useful for predicting morbidity in elderly patients undergoing colorectal cancer resection whose comorbidities are already optimized. Am J Surg. 2012;204(2):139-43.

14. Robinson TN, Wu DS, Pointer $L$, et al. Simple frailty score predicts postoperative complications across surgical specialties. Am J Surg 2013;206(4):544-50.

15. Arya S, Kim SI, Duwayri $Y$, et al. Frailty increases the risk of 30-day mortality, morbidity, and failure to rescue after elective abdominal aortic aneurysm repair independent of age and comorbidities. J Vasc Surg 2015;61(2):324-31.

16. Inouye SK, Westendorp RG, Saczynski JS. Delirium in elderly people. Lancet. 2014;383(9920):911-22.

17. Marcantonio ER. Delirium in Hospitalized Older Adults. N Engl J Med. 2017;377(15):1456-66.

18. Gnus J, Ferenc S, Dziewiszek M, et al. Comparison of endovascular aneurysm repair with open repair in patients with abdominal aortic aneurysm in our own material in years 2002-2011. Adv Clin Exp Med. 2015;24(3):475-9

19. Sangster W, Messaris E, Berg AS, et al. Single-site laparoscopic colorectal surgery provides similar clinical outcomes compared with standard laparoscopic surgery: an analysis of 626 patients. Dis Colon Rectum 2015:58(9):862-9.

20. Bagnall NM, Malietzis $\mathrm{G}$, Kennedy $\mathrm{RH}$, et al. A systematic review of enhanced recovery care after colorectal surgery in elderly patients. Color Dis. 2014;16(12):947-56.

21. Jia $Y$, Jin $G, G$ Go $S$, et al. Fast-track surgery decreases the incidence of postoperative delirium and other complications in elderly patients with colorectal carcinoma. Langenbeck's Arch Surg. 2014;399(1):77-84.

22. Launay-Savary MV, Mathonnet $M$, Theissen $A$, et al. Are enhanced recovery programs in colorectal surgery feasible and useful in the elderly? A systematic review of the literature. J Visc Surg. 2017;154(1):29-35.

23. Dekker JW, Gooiker GA, Bastiaannet E, et al. Cause of death the first year after curative colorectal cancer surgery; a prolonged impact of the surgery in elderly colorectal cancer patients. Eur J Surg Oncol. 2014;40(11):1481-7.

24. Raats JW, van Eijsden WA, Crolla RM, et al. Risk factors and outcomes for postoperative delirium after major surgery in elderly patients. PLoS One. 2015:10(8):e0136071.

25. Schiphorst AH, Verweij NM, Pronk A, et al. Non-surgical complications after laparoscopic and open surgery for colorectal cancer - a systematic review of randomised controlled trials. Eur J Surg Oncol. 2015;41(9):1118-27.

26. Witlox J, Eurelings LS, de Jonghe JF, et al. Delirium in elderly patients and the risk of postdischarge mortality, institutionalization, and dementia: a meta-analysis. JAMA. 2010;304(4):443-51.

27. Inouye SK, Bogardus ST Jr, Charpentier PA, et al. A multicomponent intervention to prevent delirium in hospitalized older patients. N Engl J Med. 1999;340(9):669-76.

28. Siddiqi N, Harrison JK, Clegg A, et al. Interventions for preventing delirium in hospitalised non-ICU patients. Cochrane Database Syst Rev. 2016;(3):CD005563.

29. Hshieh TT, Yue J, Oh E, et al. Effectiveness of multicomponent nonpharmacological delirium interventions: a meta-analysis. JAMA Intern Med. 2015:175(4):512-20.

30. Gillis $C$, Li C, Lee $L$, et al. Prehabilitation versus rehabilitation: a randomized control trial in patients undergoing colorectal resection for cancer. Anesthesiology. 2014;121(5):937-47.

31. Pouwels S, Stokmans RA, Willigendael EM, et al. Preoperative exercise therapy for elective major abdominal surgery: a systematic review. Int J Surg. 2014;12(2):134-40.

32. Santa Mina D, Clarke H, Ritvo P, et al. Effect of total-body prehabilitation on postoperative outcomes: a systematic review and meta-analysis. Physiotherapy. 2014;100(3):196-207.

33. Pouwels S, Willigendael EM, van Sambeek MR, et al. Beneficial effects of preoperative exercise therapy in patients with an abdominal aortic aneurysm: a systematic review. Eur J Vasc Endovasc Surg. 2015;49(1):66-76.

34. Li C, Carli F, Lee L, et al. Impact of a trimodal prehabilitation program on functional recovery after colorectal cancer surgery: a pilot study. Surg Endosc. 2013;27(4):1072-82.

35. Gillis C, Loiselle SE, Fiore JF Jr, et al. Prehabilitation with whey protein supplementation on perioperative functional exercise capacity in patients undergoing colorectal resection for Cancer: a pilot double-blinded randomized placebo-controlled trial. J Acad Nutr Diet. 2016:116(5):802-12.

36. Carli F, Charlebois $P$, Stein B, et al. Randomized clinical trial of prehabilitation in colorectal surgery. Br J Surg. 2010;97(8):1187-97.

37. Hijazi Y, Gondal U, Aziz O. A systematic review of prehabilitation programs in abdominal cancer surgery. Int J Surg. 2017;39:156-62.

38. Moran J, Guinan E, McCormick P, et al. The ability of prehabilitation to influence postoperative outcome after intra-abdominal operation: a systematic review and meta-analysis. Surgery. 2016;160(5):1189-201.

39. Boereboom C, Doleman B, Lund JN, et al. Systematic review of preoperative exercise in colorectal cancer patients. Tech Coloproctol. 2016;20(2):81-9.

40. Munoz M, Gomez-Ramirez S, Martin-Montanez E, et al. Perioperative anemia management in colorectal cancer patients: a pragmatic approach. World J Gastroenterol. 2014:20(8):1972-85.

41. Lopez A, Cacoub P, Macdougall IC, et al. Iron deficiency anaemia. Lancet. 2016:387(10021):907-16

42. Barberan-Garcia A, Ubre M, Roca J, et al. Personalised Prehabilitation in high-risk patients undergoing elective major abdominal surgery: a randomized blinded controlled trial. Ann Surg. 2018;267(1):50-6.

43. Acheson AG, Brookes MJ, Spahn DR. Effects of allogeneic red blood cell transfusions on clinical outcomes in patients undergoing colorectal cancer 
surgery: a systematic review and meta-analysis. Ann Surg 2012;256(2):235-44.

44. Behrends $M$, DePalma $G$, Sands $L$, et al. Association between intraoperative blood transfusions and early postoperative delirium in older adults. J Am Geriatr Soc. 2013;61(3):365-70.

45. McCusker J, Bellavance F, Cardin S, et al. Detection of older people at increased risk of adverse health outcomes after an emergency visit: the ISAR screening tool. J Am Geriatr Soc. 1999;47(10):1229-37.

46. Hackett NJ, De Oliveira GS, Jain UK, et al. ASA class is a reliable independent predictor of medical complications and mortality following surgery. Int J Surg. 2015;18:184-90.

47. Carvalho ECME, DE-Q FL, Martins DACBX, et al. The applicability of POSSUM and P-POSSUM scores as predictors of morbidity and mortality in colorectal surgery. Rev Col Bras Cir. 2018;45(1):e1347.

48. de Groot V, Beckerman H, Lankhorst GJ, et al. How to measure comorbidity. A critical review of available methods. J Clin Epidemiol. 2003;56(3):221-9.

49. Wallace M, Shelkey M. Hartford Institute for Geriatric N. Katz index of Independence in activities of daily living (ADL). Urol Nurs. 2007;27(1):93-4.

50. Oud FM, de Rooij SE, Schuurman T, et al. Predictive value of the VMS theme 'Frail elderly': delirium, falling and mortality in elderly hospital patients. Ned Tijdschr Geneeskd. 2015;159:A8491.

51. Kruizenga HM, Seidell JC, de Vet HC, et al. Development and validation of a hospital screening tool for malnutrition: the short nutritional assessment questionnaire (SNAQ). Clin Nutr. 2005;24(1):75-82.

52. Savva GM, Donoghue OA, Horgan F, et al. Using timed up-and-go to identify frail members of the older population.

J Gerontol A Biol Sci Med Sci. 2013;68(4):441-6

53. Huisman MG, van Leeuwen BL, Ugolini G, et al. "Timed Up \& Go": a screening tool for predicting 30-day morbidity in onco-geriatric surgical patients? A multicenter cohort study. PLoS One. 2014;9(1):e86863.

54. Peters DM, Fritz SL, Krotish DE. Assessing the reliability and validity of a shorter walk test compared with the 10-meter walk test for measurements of gait speed in healthy, older adults. J Geriatr Phys Ther. 2013;36(1):24-30.

55. Jones CJ, Rikli RE, Beam WC. A 30-s chair-stand test as a measure of lower body strength in community-residing older adults. Res Q Exerc Sport 1999;70(2):113-9.

56. Hulzebos EH, Helders PJ, Favie NJ, et al. Preoperative intensive inspiratory muscle training to prevent postoperative pulmonary complications in highrisk patients undergoing CABG surgery: a randomized clinical trial. JAMA. 2006;296(15):1851-7

57. Taekema DG, Gussekloo J, Maier AB, et al. Handgrip strength as a predictor of functional, psychological and social health. A prospective population-based study among the oldest old. Age Ageing. 2010;39(3):331-7.

58. Kaiser MJ, Bauer JM, Ramsch C, et al. Validation of the mini nutritional assessment short-form (MNA-SF): a practical tool for identification of nutritional status. J Nutr Health Aging. 2009;13(9):782-8.

59. Tombaugh TN, McIntyre NJ. The mini-mental state examination: a comprehensive review. J Am Geriatr Soc. 1992;40(9):922-35.

60. Creavin ST, Wisniewski S, Noel-Storr AH, et al. Mini-mental state examination (MMSE) for the detection of dementia in clinically unevaluated people aged 65 and over in community and primary care populations. Cochrane Database Syst Rev. 2016;(1):CD011145

61. Kim Kl, Park KH, Koo KH, et al. Comprehensive geriatric assessment can predict postoperative morbidity and mortality in elderly patients undergoing elective surgery. Arch Gerontol Geriatr. 2013;56(3):507-12.

62. Lee $\mathrm{YH}, \mathrm{Oh} \mathrm{HK}$, Kim DW, et al. Use of a comprehensive geriatric assessment to predict short-term postoperative outcome in elderly patients with colorectal Cancer. Ann Coloproctol. 2016;32(5):161-9.

63. Kristjansson SR, Nesbakken A, Jordhoy MS, et al. Comprehensive geriatric assessment can predict complications in elderly patients after elective surgery for colorectal cancer: a prospective observational cohort study. Crit Rev Oncol Hematol. 2010;76(3):208-17.

64. Mokutani Y, Mizushima T, Yamasaki M, et al. Prediction of postoperative complications following elective surgery in elderly patients with colorectal Cancer using the comprehensive geriatric assessment. Dig Surg. 2016:33(6):470-7.

65. Partridge JS, Harari D, Martin FC, et al. The impact of pre-operative comprehensive geriatric assessment on postoperative outcomes in older patients undergoing scheduled surgery: a systematic review. Anaesthesia. 2014:69(Suppl 1):8-16.

66. Schroevers MJ, Sanderman R, van Sonderen E, et al. The evaluation of the Center for Epidemiologic Studies Depression (CES-D) scale: depressed and positive affect in cancer patients and healthy reference subjects. Qual Life Res. 2000;9(9):1015-29.

67. Van Dam NT, Earleywine M. Validation of the Center for Epidemiologic Studies Depression Scale--Revised (CESD-R): pragmatic depression assessment in the general population. Psychiatry Res. 2011;186(1):128-32.

68. Robinson BC. Validation of a caregiver strain index. J Gerontol. 1983;38(3):344-8.

69. Development of the World Health Organization WHOQOL-BREF quality of life assessment. The WHOQOL group. Psychol Med. 1998;28(3):551-8.

70. Ware JE Jr, Sherbourne CD. The MOS 36-item short-form health survey (SF36). I. Conceptual framework and item selection. Med Care. 1992;30(6):473-83.

71. de Vries R, Haas F, working group for revision of the Dutch Blood Transfusion G. English translation of the dutch blood transfusion guideline 2011. Clin Chem. 2012;58(8):1266-7.

72. Keeler BD, Simpson JA, Ng S, et al. The feasibility and clinical efficacy of intravenous iron administration for preoperative anaemia in patients with colorectal cancer. Color Dis. 2014;16(10):794-800.

73. Iron deficiency anaemia. Assessment, prevention and control. A guide for programme managers.: World Health Organisation; 2001. Available from: https://www.who.int/nutrition/publications/en/ida_assessment_prevention_ control.pdf.

74. Rognoni C, Venturini S, Meregaglia M, et al. Efficacy and safety of ferric Carboxymaltose and other formulations in Iron-deficient patients: a systematic review and network meta-analysis of randomised controlled trials. Clin Drug Investig. 2016;36(3):177-94.

75. Inouye SK, Bogardus ST Jr, Baker DI, et al. The hospital elder life program: a model of care to prevent cognitive and functional decline in older hospitalized patients. Hospital elder life program. J Am Geriatr Soc. 2000;48(12):1697-706.

76. Schuurmans MJ, Shortridge-Baggett LM, Duursma SA. The delirium observation screening scale: a screening instrument for delirium. Res Theory Nurs Pract. 2003:17(1):31-50.

77. American Psychiatric Association. Diagnostic and statistical manual of mental disorders. 5th ed. Arlington, VA: Author; 2013.

78. Inouye SK, van Dyck CH, Alessi CA, et al. Clarifying confusion: the confusion assessment method. A new method for detection of delirium. Ann Intern Med. 1990;113(12):941-8.

79. Dindo D, Demartines N, Clavien PA. Classification of surgical complications: a new proposal with evaluation in a cohort of 6336 patients and results of a survey. Ann Surg. 2004;240(2):205-13.

80. Clavien PA, Barkun J, de Oliveira ML, et al. The Clavien-Dindo classification of surgical complications: five-year experience. Ann Surg. 2009:250(2):187-96

81. Kohut AY, Liu JJ, Stein DE, et al. Patient-specific risk factors are predictive for postoperative adverse events in colorectal surgery: an American College of Surgeons National Surgical Quality Improvement Program-based analysis. Am J Surg. 2015;209(2):219-29.

82. Chan AW, Tetzlaff JM, Altman DG, et al. SPIRIT 2013 statement: defining standard protocol items for clinical trials. Ann Intern Med. 2013;158(3):200-7.

83. Standardisation Report 5: SONCOS: Stichting Oncologische Samenwerking, Standardisation of Multidisciplinary Cancer Care in The Netherlands; 2017. Available from: https://www.nvog.nl/wp-content/uploads/2018/02/SONCOSnormeringsrapport-versie-5-2017.pdf.

\section{Ready to submit your research? Choose BMC and benefit from:}

- fast, convenient online submission

- thorough peer review by experienced researchers in your field

- rapid publication on acceptance

- support for research data, including large and complex data types

- gold Open Access which fosters wider collaboration and increased citations

- maximum visibility for your research: over $100 \mathrm{M}$ website views per year

At $\mathrm{BMC}$, research is always in progress.

Learn more biomedcentral.com/submissions 